\title{
EVALUATION OF MASS TRANSFER EVAPOTRANSPIRATION MODELS UNDER SEMIARID CONDITIONS USING MCDM APPROACH
}

\author{
ISlAM, S. ${ }^{1 *}-$ ABDUllah, R. A. B. ${ }^{1}-$ TIRTH, V. ${ }^{2}-$ Shahid, S. ${ }^{1}-$ Algarni, S. ${ }^{2}-$ HIROL, H. ${ }^{1}$ \\ ${ }^{1}$ Department of Civil Engineering, University Teknologi Malaysia, P.O. Box 81310 Johor \\ Bahru, Johor, Malaysia \\ ${ }^{2}$ Department of Mechanical Engineering, College of Engineering, King Khalid University, Abha \\ 61413 Asir, Kingdom of Saudi Arabia \\ *Corresponding author \\ e-mail: isaiful2@graduate.utm.my; phone: +966-59-521-9933; fax: +966-17-241-8816 \\ (Received 21 ${ }^{\text {st }}$ Mar 2020; accepted $11^{\text {th }}$ Aug 2020)
}

\begin{abstract}
The selection of suitable reference evapotranspiration (ETo) models in case of climatic data scarcity is a challenging task as it plays a pivotal role in agriculture and water resource management. Therefore, the research work deals with selecting the appropriate mass transfer reference evapotranspiration model using multi criteria decision technique (MCDM) in a semi-arid region of the southern part of Kingdom of Saudi Arabia i.e., Abha. The ten mass transfer methods with ten criteria (statistical indices) using available weather parameters from 1980 to 2018 have been illustrated in this study. Models were calibrated (1980-2006) and validated for the period (2007-2018). The objective weight was computed by criteria importance through inter criteria correlation (CRITIC) method and performance score by weighted sum model (WSM), weighted product model (WPM), weighted aggregates sum product assessment (WASPAS) and evaluation based on distance from average solution (EDAS) methods which in turn rank the evapotranspiration method. The rankings obtained from MCDM techniques were validated with ranking by GPI method using spearman ranking coefficient. The result from MCDM shows that Saif model is the best model and that also GPI yielded same result. The methodology applied in this study can be adopted in any other region which in turns proved to be beneficial for crop cultivators, crop advisors, researchers, and water resource management.
\end{abstract}

Keywords: water management, CRITIC, WSM, WPM, WASPAS, EDAS

\section{Introduction}

The reliable estimation of reference evapotranspiration (ETo) is a crucial part of regional water resources planning, net irrigation requirement, agriculture water requirements and to model the climate change effect (Pandey et al., 2016). The ETo can be measured directly by lysimeter, but the procedure is time consuming and expensive (Mehdizadeh, 2018). The ETo could be indirectly calculated using a site-specific energy balance or empirical models that typically includes meteorological data, altitude, and latitude. Of the indirect methods, FAO56-PM is the most effective method for the precise estimation of ETo (Allen et al., 1998; Berti et al., 2014). However, it demands high and reliable data quality which is difficult to achieve (Valiantzas, 2013). The precise quantification of the ETo forecasts is dependent on meteorological input data (Allen, 2008). The lack of climate data leads to the need for a simple empirical equation requiring less climate parameters, such as mass transfer, radiation and temperature methods (Sentelhas et al., 2010). Researchers in different regions such as India, Bosnia, Africa, China and Saudi Arabia have developed and applied many empirical equations (Pandey and Pandey, 2018; Cadro et al., 2017; Djaman et al., 2017; Lang et al., 2017; 
Alblewi et al., 2015) as an alternative to lysimeter or standard FAO56-PM. However, mass transfer-based models involving lesser climatic parameters are among the most commonly used (Valipour, 2017). Such empirical equation should be assessed and validated against lysimetric or standard FAO56-PM technique due to regional constraints (Bogawski and Bednorz, 2014). In previous research, mass transfer methods typically only include evaluation of the studied model. Few research conducted evaluation calibration as well as validation of mass transfer equation (Djaman et al., 2016). In addition, rankings using performance assessment of different models are rarely studied against Standard FAO56-PM (Almorox et al., 2015). Alternatively, previous studies adopt few questionable statistical indices for performance evaluation of reference evapotranspiration, such as RMSE or MBE (Muhammad et al., 2019). Therefore, multiple statistical indices must be used to assess the performance of the mass transfer equation in order to obtain a realistic result. However, it is a challenging task for decision-makers (DMs) to find optimum decision. Therefore, powerful tool is desired for the final selection. Recently, researchers applied multi-criteria decision making (MCDM) techniques in the field of water resource management (Minatour et al., 2015; Makropoulos et al., 2008). To date, different MCDM methods have been developed for ranking purpose (Mardani et al., 2016) such as Water reservoirs (Srdjevic et al., 2004), urban water management (Zarghami et al., 2008), groundwater management (Pietersen, 2006), water conservation (Janssen et al., 2005), and irrigation planning (Gupta et al., 2000). Senent-Aparicio et al. (2017) assesses the effects of climate change in the Segura river basin (SE Spain) using SWAT and Fuzzy TOPSIS. Many studies have been carried out in the Kingdom of Saudi Arabia to estimate various ETo models against the FAO-56 Penman Monteith models (Abo-Ghobar and Mohammad, 1995; Al-Omran et al., 2004; ElNesr et al., 2010; Islam et al., 2019 a, b; Islam et al., 2020). In the study region, the ranking of mass transfer-based equation was rarely studied using MCDM. The goal of this study is to estimate (evaluate) ETo using ten mass transfer equations for the period between 1980-2018 and to further improve its efficiency, it is calibrated for the period between 1980-2006 and validated against standard FAO56-PM for the period between 2007-2018 and finally ranked by MCDM technique. The suggested methodology in the present study could be used in future for selecting best reference evapotranspiration model as a substitute to standard FAO56-PM in any region around the world. Also, the calibration improves the preciseness of ETo estimation. Moreover, the best selected model for estimating ETo could be used by agriculturist, hydrologist, policy and decision makers for the strategic planning of water resource management in the future.

\section{Materials and methods}

The present research was conducted to evaluate the performance of mass transferbased ETo under limited climatic condition against standard FAO56-PM during evaluation (1980-2018), calibration (1980-2006) and validation (2007-2018) under semi-arid scenario Abha, KSA. The weather data is taken from Abha meteorological department at GPS location $18^{\circ} 14^{\prime} \mathrm{N}, 42^{\circ} 39^{\prime}$ E. Such partitioning of calibration and validation period is attributed to the need for more data to train the algorithms, as suggested by Valipour (2015). The performance of these equations has been based on ten statistical criteria. The model ranking was based on MCDM techniques, where weightage is obtained by CRITIC method, while ranking by WSM, WPM, WASPAS 
and EDAS method. The ranking results from MCDM were compared with the outcome of GPI. The spearman ranking correlation was used to check the accuracy of the MCDM ranking. The fundamental objective of this study work is to choose the best model in the study region to replace the FAO56-PM model since this model required several climatic parameters that were sometimes difficult to achieve in the mountainous Abha region due to signal connectivity problems. Moreover, to select FAO56-PM as a standard against mass transfer models. The first important step is to validate its accuracy with respect to experimentally measured data.

The stepwise methodology adopted in the study is described by the flowchart in Figure 1.

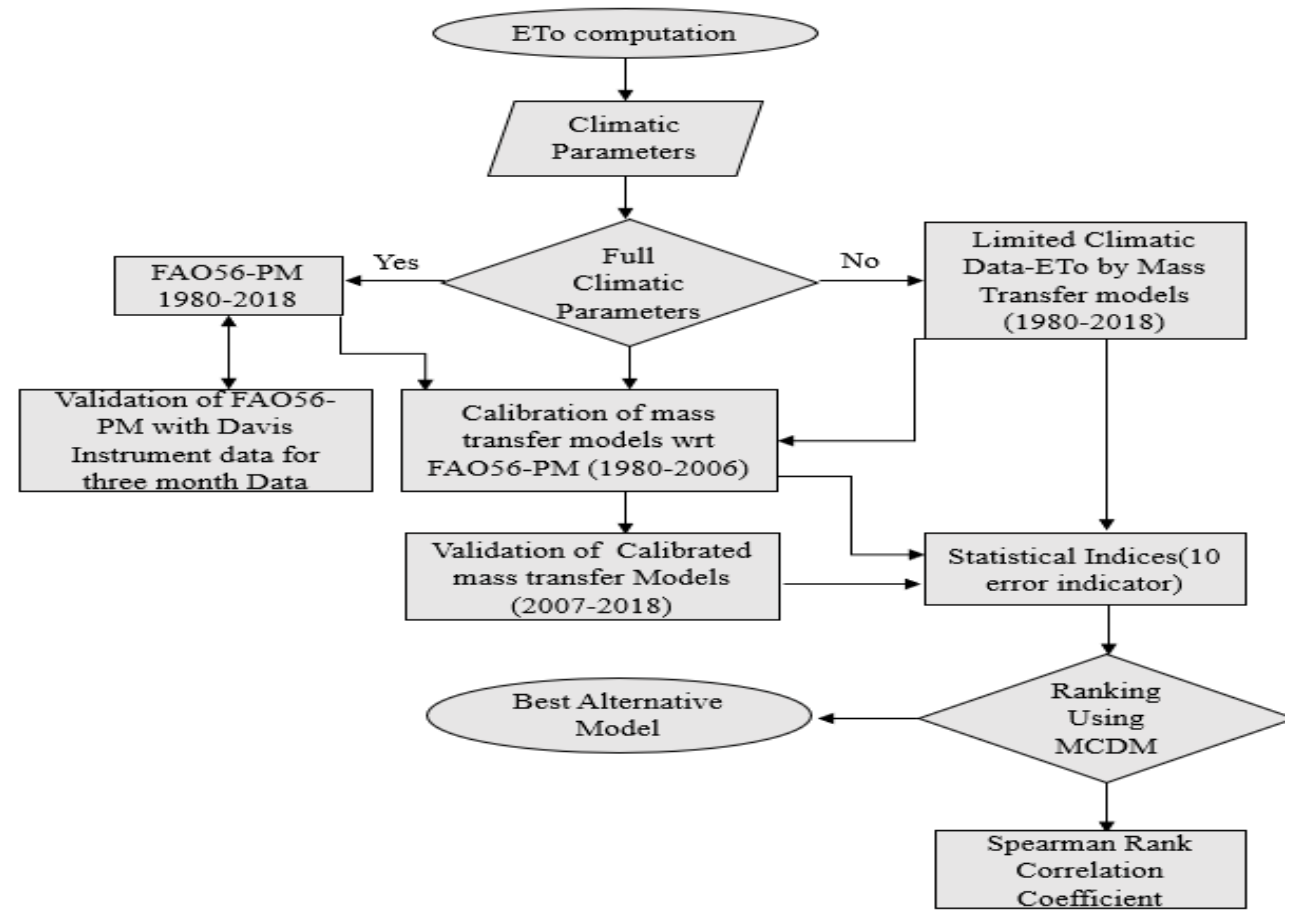

Figure 1. Methodology (stepwise computation)

\section{Experimental setup}

For the validation of the FAO56-PM model The measurement of the Davis Vantage Pro2 weather station at GPS location $18^{\circ} 15^{\prime} 06^{\prime \prime} \mathrm{N}, 42^{\circ} 33^{\prime} 27^{\prime \prime} \mathrm{E}$ was taken for a period of three months, i.e. from February to April, 2019. The schematic diagram for the weather station is given in Figure 2. The integrated instrument includes all sensors - anemometer, rain collector, temperature, humidity and solar irradiance - for measuring all required climatic parameters as well as measured evapotranspiration. The specific aim of reading from the Davis instrument is to verify the result from estimates of FAO56-PM using climatic data obtained from measurement of sensors against measured ETo from the weather station so that it can be used as a reference for other mass transfer model, as the FAO56-PM model is used in this analysis for evaluation, calibration and validation purposes. The outcome of plots of estimated FAO56-PM against measured ETo from Davis instrument reading (Fig. 3) indicates that there is a strong association between two readings with a very small error as indicated from the figure. 


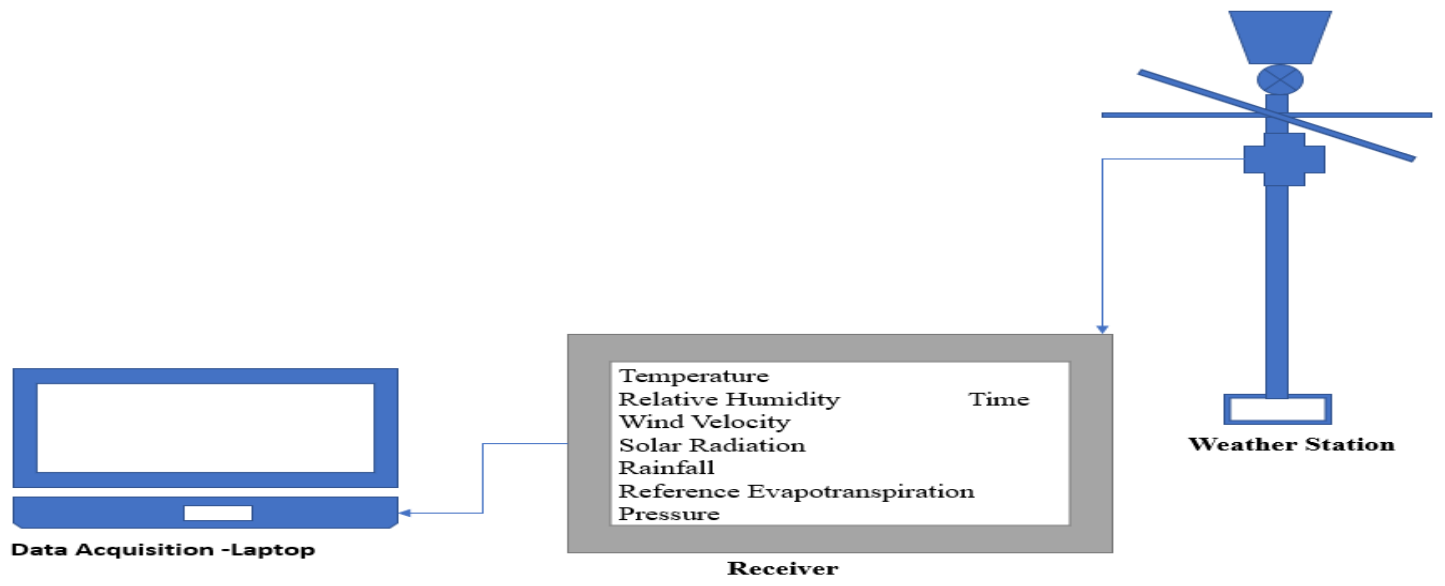

Figure 2. Schematic diagram for experimental setup of Davis weather station

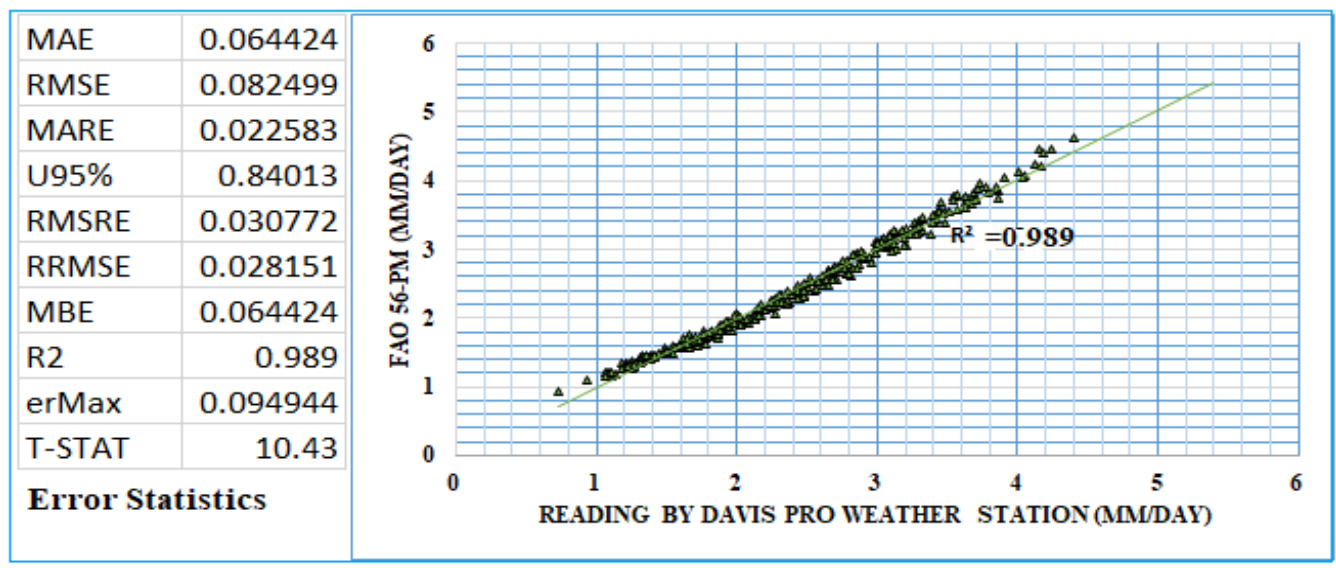

Figure 3. Validation of FAO56-PM with Davis weather station (Abha)

\section{FAO56-PM and mass transfer model description}

The estimation of reference evapotranspiration was done using well-recognized model i.e., FAO56-PM as given by Equation 1 as well as ten mass transfer equation as given by Equations 2-11 under data limitation in the study region between 1980-2018. Models selected for the study region are largely accepted under similar climatic conditions. Models are mentioned below.

Standard model (FAO 56-PM) (Allen et al., 1998)

$$
\text { ETo }=\frac{0.408 \times \Delta \times(R n-G)+\gamma \times\left(\frac{900}{T+273}\right) \times u_{2} \times\left(e_{s}-e_{a}\right)}{\Delta+\gamma \times\left(1+0.34 u_{2}\right)}
$$

Empirical models (mass transfer)

Dalton (1802)

$$
\text { ETo }=\left(0.3648+0.07223 u_{2}\right) \times\left(e_{s}-e_{a}\right)
$$


Trabert (1896)

$$
\text { ETo }=0.408 \times 0.3075 \times \sqrt{u_{2}} \times\left(e_{s}-e_{a}\right)
$$

Meyer (1926)

$$
\text { ETo }=\left(0.375+0.05026 u_{2}\right) \times\left(e_{s}-e_{a}\right)
$$

Rohwer (1931)

$$
E T o=0.44\left(1+0.27 u_{2}\right) \times\left(e_{s}-e_{a}\right)
$$

Penman (1948)

$$
\text { ETo }=0.35 \times\left(1+0.24 u_{2}\right) \times\left(e_{s}-e_{a}\right)
$$

Albrecht (1950)

$$
\text { ETo }=\left(0.1005+0.297 u_{2}\right) \times\left(e_{s}-e_{a}\right)
$$

Brockamp (1963)

$$
E T o=\left(0.543 u_{2}^{0.456}\right) \times\left(e_{s}-e_{a}\right)
$$

WMO (1966)

$$
\text { ETo }=\left(0.1298+0.0934 u_{2}\right) \times\left(e_{s}-e_{a}\right)
$$

Mahringer (1970)

$$
E T o=0.15072 \times \sqrt{3.6 u_{2}} \times\left(e_{s}-e_{a}\right)
$$

Saif $(2019 b)$

$$
\text { ETo }=\left(0.37+0.72 u_{2}\right) \times\left(e_{s}-e_{a}\right)
$$

where ETo is in $\mathrm{mm}$ day $^{-1}$. $\mathrm{Rn}$ and $\mathrm{G}$ represent net radiation and heat flux density of soil $\left(\mathrm{MJm}^{-2}\right.$ day $\left.^{-1}\right)$ respectively. $\mathrm{u}_{2}$ represent the velocity of wind at $2 \mathrm{~m}$ height $\left(\mathrm{m} \mathrm{s}^{-1}\right)$. $\mathrm{T}$ represents mean temperature at height of $2 \mathrm{~m}\left({ }^{\circ} \mathrm{C}\right) .\left(\mathrm{e}_{\mathrm{s}}-\mathrm{e}_{\mathrm{a}}\right)(\mathrm{kPa})$ represent vapour pressure deficit. $\Delta$ and $\gamma$ denoted vapor pressure curve (slope) and psychrometric constant $\left(\mathrm{kPa}^{\circ} \mathrm{C}^{-1}\right)$ respectively. $\mathrm{RH}_{\text {mean }}=$ Mean Relative Humidity $(\%)$.

\section{Calibration and validation of ETo equations}

To calibrate Mass Transfer Models. The graph between mass transfer equation and standard FAO56-PM equation was plotted and regression analysis was performed (Allen et al., 1998). The calibration technique adopted was defined by Equation 12: 


$$
E T_{F A 056-P M}=a \cdot E T_{E M P}+b
$$

where $\mathrm{ET}_{\mathrm{FAO} 6 \text { PM }}$ denotes estimated result by FAO56-PM model while ET EMP denotes the various empirical equation using in the present study (10-mass transfer equations). The constant a (slope) and b (intercept) called as calibrated empirical coefficients. The calibrated equations must have slope (a) close to unity while intersept (b) should be near to zero for best result. In order to estimate calibrated coefficient a (slope) multiply the slope of a regression line by inversing the slope in order to make the slope of equation closer to unity. Also to get $b$ (intercept) closer to zero opposite sign value of intercept was added for new regression equation (Xu et al., 2013).

\section{Evaluation criteria and global performance index (GPI)}

For the GPI computation (Eq. 13), various statistical indices (error indictor) as described by Equations 14-23 is required prior to the estimation of GPI. (Ali et al., 2019). The ideal value of all indices equals zero except for $\mathrm{R}^{2}$ it is taken as 1 . Despotovic et al. (2015) used the concept of GPI by normalizing the errors between the scale of 0 to 1 and further subtracting it from the equivalent medians then adding up the differences so obtained using the weight factors. The expression for GPI for the $i^{\text {th }}$ model is as follows:

$$
G P I_{i}=\sum_{j=1}^{10} \alpha_{j}\left(\tilde{y}_{j}-\tilde{y}_{i j}\right)
$$

where $\alpha_{j}$ depends on statistical values (+1 value for recommended value 0 and -1 for recommended value 1 (e.g. $\mathrm{R}^{2}$ ). $\tilde{y}_{j}$ and $\tilde{y}_{i j}$ are the median and scaled values, respectively.

Willmott and Matsuura (2005) applied MAE in their study as given by Equation 14.

Mean absolute error (MAE)

$$
M A E=\frac{1}{n} \sum_{i=1}^{n}\left|E T_{0, M i}-E T_{o, F A 056-P M}\right|
$$

Root mean square error

$$
R M S E=\left[\frac{1}{n} \sum_{i=1}^{n}\left(E T_{O, M i}-E T_{o, F A O 56-P M}\right)^{2}\right]^{\frac{1}{2}}
$$

Mean absolute relative error (MARE)

$$
M A R E=\frac{1}{n} \sum_{i=1}^{n}\left|\frac{E T_{O, M i}-E T_{O, F A O 56-P M}}{E T_{O, M i}}\right|
$$

In the modelling of solar radiations, Behar et al. (2015) and Gueymard (2014) used $\mathrm{U}_{95}$ as given by Equation 17:

Uncertainty at $95 \%$

$$
U_{95}=1.96\left(S D^{2}+R M S E^{2}\right)^{\frac{1}{2}}
$$


Root mean squared relative error

$$
R M S R E=\sqrt{\frac{1}{n} \sum_{i=1}^{n}\left(\frac{E T_{O, M i}-E T_{o, F A O 56-P M}}{E T_{O, M i}}\right)^{2}}
$$

Also in the modelling of global solar radiation, Li et al. (2013) applied RRMSE as given by Equation 19:

Relative root mean square error

$$
R R M S E=100 \times \frac{\sqrt{\frac{1}{n} \sum_{i=1}^{n}\left(E T_{O, M i}-E T_{o, F A 056-P M}\right)^{2}}}{\sum_{i=1}^{n} E T_{O, M i}}
$$

Mean bias error

$$
M B E=\frac{1}{n} \sum_{i=1}^{n}\left(E T_{0, M i}-E T_{o, F A 056-P M}\right)
$$

Correlation coefficient

$$
R^{2}=1-\frac{\sum_{i=1}^{n}\left(E T_{O, M i}-E T_{o, F A O 56-P M}\right)^{2}}{\sum_{i=1}^{n}\left(E T_{O, M i}-E T_{O, M i}\right)_{a v}}
$$

Maximum absolute relative error

$$
\operatorname{erMAX}=\max \left(\left|\frac{E T_{O, M i}-E T_{O, F A O 56-P M}}{E T_{O, M i}}\right|\right)
$$

Moreover, Stone (1993) and Mulaudzi et al. (2015) applied t-statistics in the evaluation of solar radiation as shown by Equation 23:

$$
t=\left\lceil\left.\frac{(n-1) M B E^{2}}{R M S E^{2}-M B E^{2}}\right|^{\frac{1}{2}}\right.
$$

\section{Multi criteria decision technique}

For the implementation of MCDM techniques the weightages were computed using CRITIC method and for measuring the performance score of various empirical equations (alternatives), the models i.e., WSM, WPM, WASPAS and EDAS were used using the same statistical indices as implemented in GPI (criteria). Of all the criteria, the $\mathrm{R}^{2}$ criteria is referred to as beneficial criteria and the other nine are non-beneficial criteria. The performance values (the higher the value the better the model will be) of the different ETo models will determine the promising model in the Abha region, which is one of the novelty in this research work. The adopted technique is as defined by Figure 4.

\section{Objective weight}

The objective weight is computed by criteria importance through inter criteria correlation (CRITIC) method. The method is first proposed by Diakoulaki et al. (1995) 
and it is objective weighting methods. In order to find the contrast between criteria correlation analysis are done (Adalı and Iş1k, 2017). There is $\mathrm{m}$ feasible alternatives, $\mathrm{A}_{\mathrm{i}}$ $(i=1,2, \ldots, m)$ and $n$ evaluation criteria $C_{j}(j=1,2, \ldots, n)$ in the problem. The stepwise methodology is described below:

Step 1 To establish decision matrix $\mathrm{X}$ showing alternatives performance as compared to various criteria.

Step 2 The normalization of decision matrix is done using Equation 24:

$$
r_{i j}=\frac{x_{i j-x_{j}^{\min }}}{x_{j}^{\max }-x_{j}^{\min }}
$$

where $\mathrm{r}_{\mathrm{ij}}$ represent performance value of normalized decision matrix of $\mathrm{i}^{\mathrm{th}}$ alternative on $\mathrm{j}^{\text {th }}$ criterion.

Step 3 The weight of the $\mathrm{j}^{\text {th }}$ criterion $\left(\mathrm{w}_{\mathrm{j}}\right)$ is obtained as by Equation 25 , where $\mathrm{C}_{\mathrm{j}}$ is given by Equation 26:

$$
w_{j}=\frac{c_{j}}{\sum_{i=1}^{m} c_{j}}
$$

where

$$
C_{j}=\sigma_{j} \sum_{i=1}^{m}\left(1-r_{i j}\right)
$$

$\mathrm{C}_{\mathrm{j}}$ is the quantity of information contained in $\mathrm{j}^{\text {th }}$ criterion, $\sigma_{\mathrm{j}}$ is standard deviation of the $\mathrm{j}^{\text {th }}$ criterion and $\mathrm{r}_{\mathrm{jj}}{ }^{\prime}$ is the correlation coefcient between $\mathrm{j}^{\text {th }}$ and $\mathrm{j}^{\text {th }}$ criteria.

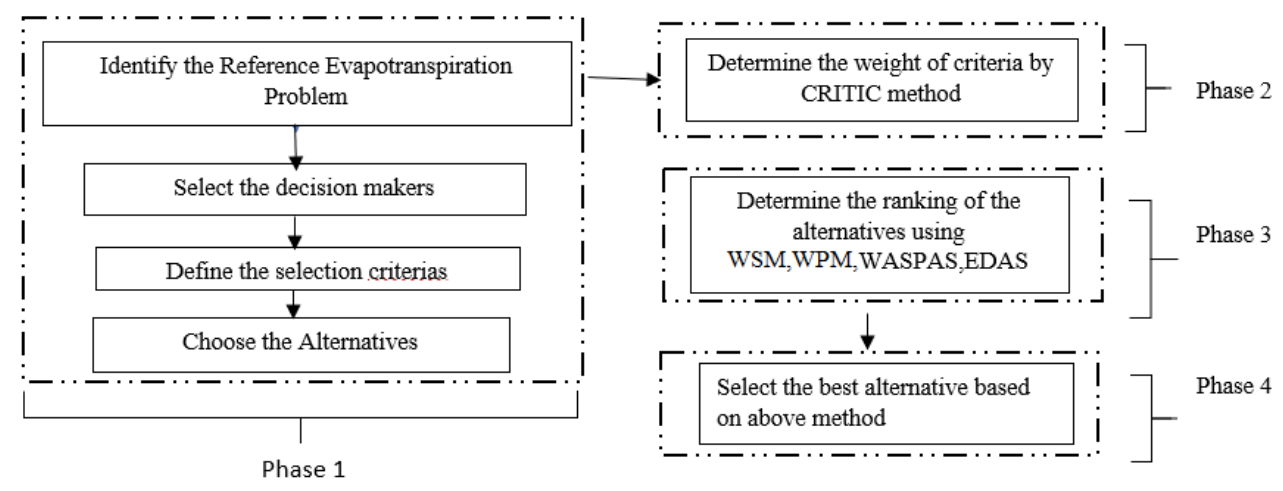

Figure 4. Application of MCDM in selecting best ETo model

\section{Performance score}

Weighted sum model (WSM) (Mann and Evangelos, 1989): The importance of $i^{\text {th }}$ alternative by WSM technique is computed using Equation 27:

$$
Q_{i}^{(1)}=\sum_{j=1}^{n} \bar{x}_{i j} w_{j}
$$

Weighted Product Model (WPM) (Mann and Evangelos, 1989): The importance of $\mathrm{i}^{\text {th }}$ alternative by WPM technique is computed using Equation 28: 


$$
Q_{i}^{(2)}=\prod_{j=1}^{n}\left(\bar{x}_{i j}\right)^{w_{j}}
$$

Weighted Aggregates Sum Product Assessment (WASPAS) method: A joint generalized criterion of weighted aggregation of additive and multiplicative method is then proposed as given by Equation 29 (Šaparauskas et al., 2011).

$$
Q_{i}=0.5 Q_{i}^{(1)}+0.5 Q_{i}^{(2)}=0.5 \sum_{j=1}^{n} \bar{x}_{i j} w_{j}+0.5 \prod_{j=1}^{n}\left(\bar{x}_{i j}\right)^{w_{j}}
$$

Evaluation based on Distance from Average Solution (EDAS) method:

The methodology is adopted as studied by Keshavarz et al. (2015). The stepwise computation by EDAS method is described below:

Step 1. Criteria and alternatives are decided based on need of problem.

Step 2. Decision matrix of $\mathrm{X}$ based on selected criteria and alternatives are established as given by Equation 30:

$$
X=\left|X_{i j}\right|_{n \times m}=\left[\begin{array}{ccc}
x_{11} & x_{12} \ldots & x_{1 m} \\
\vdots & \vdots & \vdots \\
x_{n 1} & x_{n 2} \ldots & x_{n m}
\end{array}\right]
$$

where $\mathrm{x}_{\mathrm{ij}}$ represents the value of $\mathrm{i}^{\text {th }}$ alternative with respect to $\mathrm{j}^{\text {th }}$ criterion based on performance.

Step 3. AV based on all criteria are determined using Equations 31-32:

$$
\begin{gathered}
A V=\left[A V_{j}\right]_{1 \times m^{\prime}}, j=1, \ldots \ldots, m . \\
A V_{j}=\frac{\sum_{i=1}^{n} X_{i j}}{n}, j=1, \ldots \ldots, m .
\end{gathered}
$$

Step 4. The PDA and NDA matrices are calculated based on the type of Criteria as given by Equations 33-38:

$$
\begin{aligned}
P D A & =\left[P D A_{i j}\right]_{n \times m} \\
N D A & =\left[N D A_{i j}\right]_{n \times m}
\end{aligned}
$$

If criterion $\mathrm{j}$ is benefit criteria,

$$
\begin{aligned}
P D A_{i j} & =\frac{\max \left(0,\left(x_{i j}-A V_{j}\right)\right)}{A V_{j}} \\
N D A_{i j} & =\frac{\max \left(0,\left(A V_{j}-x_{i j}\right)\right)}{A V_{j}}
\end{aligned}
$$

If criterion $\mathrm{j}$ is non beneficial criterion, 


$$
\begin{gathered}
P D A_{i j}=\frac{\max \left(0,\left(A V_{j}-x_{i j}\right)\right)}{A V_{j}} \\
N D A_{i j}=\frac{\max \left(0,\left(x_{i j}-A V_{j}\right)\right)}{A V_{j}}
\end{gathered}
$$

Here, $\mathrm{PDA}_{\mathrm{ij}}$ and $\mathrm{NDA}_{\mathrm{ij}}$ indicate the positive and negative distances of $\mathrm{i}^{\text {th }}$ alternative from AV in terms of jth criterion, respectively.

Step 5. Weighted sum of PDA and NDA for all alternatives are determined by using Equations 39-40:

$$
\begin{aligned}
S P_{i} & =\sum_{j=1}^{m} w_{j} P D A_{i j} \\
S N_{i} & =\sum_{j=1}^{m} w_{j} N D A_{i j}
\end{aligned}
$$

Here $\mathrm{W}_{\mathrm{j}}$ indicates the weight of $\mathrm{j}^{\text {th }}$ criterion. 42):

Step 6. For all alternatives, SP and SN values are normalised by using Equations 41-

$$
\begin{gathered}
N S P_{i}=\frac{S P_{i}}{\max \left(S P_{i}\right)} \\
N S N_{i}=1-\frac{S N_{i}}{\max \left(S N_{i}\right)}
\end{gathered}
$$

Step 7. Appraisal score (AS) for all alternatives are calculated as:

$$
A S_{i}=\frac{1}{2}\left(N S P_{i}+N S N_{i}\right)
$$

where $0 \leq \mathrm{AS}_{\mathrm{i}} \leq 1$.

Step 8. According to the obtained AS, alternatives are ranked in descending order. The alternative with the highest AS is the best one among the other alternatives.

\section{Results and discussion}

This study presents a comparison (evaluation 1980-2018, calibration 1980-2006 and validation 2007-2018) of the selected ten mass transfer reference equations (alternatives) to the standard FAO56-PM. The models of mass transfer based were chosen in the study because of their rigor and comprehensiveness as defined by various researchers in the field of water resource management (e.g. Ali and Shui, 2009; Tabari et al., 2013). Average Monthly ETo per day ( $\mathrm{mm} / \mathrm{day}$ ) during evaluation, calibration and validation period is given in Tables 1-3 while the seasonal variation as shown by Table 4 . The performance of different mass transfer equations was evaluated through 
ten statistical indices (criteria) as described in the methodology. The criterion weight of the different indices was determined using the CRITIC method, whereas four MCDM techniques i.e., WSM WPM, WASPAS and EDAS were used to rank the mass transfer method. In addition, the GPI ranking has been computed to validate the result using MCDM techniques. The rank correlation coefficient for Spearman was determined between MCDM and GPI technique to check the accuracy of MCDM technique. When comparing the reference evapotranspiration by selected mass transfer model with standard FAO56-PM in terms of correlation coefficient and error indices (Fig. 5) during the evaluation process, it was observed that all selected equations bears a strong correlation ( $\mathrm{R}^{2}$ ranges 0.89 to 0.96 ) with FAO56-PM with the highest correlation observed in the Saif model and lower by Trabert model. In addition, when evaluating the output of the same equations in terms of the error indicator, Saif model achieved the highest precision. The results assessed from 1980-2018 showed that some of the method of mass transfer performed better without calibration like Albrecht and Saif model, which is in agreement with Islam et al. (2019b). Similar findings were previously obtained after evaluating six ETo equations for the Senegal River Delta (Djaman et al., 2016). The results are in accordance with the analysis done by Djaman et al. (2015) under Sahelian conditions in the Senegal river valley. These models use the temperature and wind speed observation to estimate the ETo values (Shiri, 2018). Though in certain regions such models may provide accurate results (Xu and Singh, 2002; Tabari et al., 2013). The accuracy of the results of these models as described in Kiafar et al. (2017) may be reduced by low aerodynamic effects. Moreover, wind speed and air temperature were determined at different altitudes resulting in a significant number of related or equivalent equations. Therefore, it will be difficult to apply data from one location and/or height to another and apply a model developed in a specified region at another location with certainty (Shiri, 2018). Like the other ETo models, local calibration is a big drawback of such models. To overcome such problems, the comparison was made again with regard to correlation coefficients and error indicators while calibrating the whole equation against standard FAO56-PM (Fig. 6), All chosen equations were shown to have a high correlation $\left(\mathrm{R}^{2}\right.$ ranges 0.91 to 0.98$)$ with the FAO56-PM with the highest correlation detected in the Saif model and lower in the Meyer and Trabert model. The Saif model also achieved the highest accuracy while observing the performance of the same equations in terms of the error indicator. The models are calibrated similar to the studies of Irmak et al. (2003) and Xu and Singh (2001). It has been found from the inspection of the output during calibration that the model calibration significantly enhanced the efficiency of all equations. Also same result noticed while validating the calibrated equations (Fig. 7) with $\left(\mathrm{R}^{2}\right.$ ranges from 0.872 to 0.921$)$. The high correlation observed by Saif model and lower by Trabert model. Which is similar to result obtained by Bogawski and Bednorz, 2014 in study in Poland. Conversely Meyer equation perform better in north-western Ontario, Canada (Singh and $\mathrm{Xu}, 2002$ ) Also while observing the performance of same equations in terms of error indicator the highest accuracy was achieved by Saif model. The result obtained is in agreement with Islam et al. (2019b). Additionally, the findings of the research are in agreement with Kisi and Zounemat Kermani (2014). From the study it has been confirmed that in some region overestimated the ETo by Mass transfer (Valipour, 2015; Winter et al., 1995) while other underestimated (Tabari et al., 2013; Djaman et al., 2015). Azhar and Perera (2011) and Zhai et al. (2010) calibrated ETo models and concluded that calibration can be used to modify ETo with multi-station data to improve its accuracy. Bormann (2011) 
examined various models of mass transfer to examine climate change in Germany and noticed a substantial difference in the performance of all models. Therefore, MCDM technique was applied to rank different model based on performance.

Table 1. Average monthly ETo per day (mm/day) during evaluation period 1980-2018

\begin{tabular}{c|c|c|c|c|c|c|c|c|c|c|c}
\hline Month & FAO56-PM & Dalton & Trabert & Meyer & Rohwer & Penman & Albrecht & Brockamp & WMO & Mahringer & Saif \\
\hline Jan & 1.84 & 0.4 & 0.15 & 0.36 & 0.54 & 0.54 & 0.67 & 0.61 & 0.28 & 0.34 & 1.72 \\
Feb & 1.91 & 0.38 & 0.14 & 0.34 & 0.52 & 0.52 & 0.66 & 0.59 & 0.27 & 0.32 & 1.69 \\
Mar & 1.95 & 0.39 & 0.15 & 0.35 & 0.54 & 0.54 & 0.7 & 0.61 & 0.29 & 0.34 & 1.79 \\
Apr & 2.59 & 0.59 & 0.22 & 0.54 & 0.8 & 0.78 & 0.94 & 0.9 & 0.4 & 0.49 & 2.42 \\
May & 2.84 & 0.76 & 0.27 & 0.71 & 1.03 & 0.99 & 1.13 & 1.14 & 0.5 & 0.62 & 2.92 \\
Jun & 3.85 & 1.09 & 0.39 & 1 & 1.47 & 1.43 & 1.66 & 1.64 & 0.72 & 0.9 & 4.29 \\
Jul & 3.18 & 0.86 & 0.31 & 0.79 & 1.16 & 1.13 & 1.34 & 1.3 & 0.57 & 0.71 & 3.44 \\
Aug & 3.12 & 0.84 & 0.3 & 0.77 & 1.13 & 1.1 & 1.31 & 1.26 & 0.56 & 0.69 & 3.37 \\
Sep & 3.52 & 0.96 & 0.34 & 0.88 & 1.29 & 1.24 & 1.43 & 1.43 & 0.63 & 0.78 & 3.69 \\
Oct & 2.89 & 0.73 & 0.26 & 0.68 & 0.97 & 0.93 & 1.04 & 1.08 & 0.46 & 0.59 & 2.69 \\
Nov & 1.62 & 0.38 & 0.13 & 0.35 & 0.51 & 0.49 & 0.55 & 0.56 & 0.24 & 0.31 & 1.42 \\
Dec & 1.5 & 0.35 & 0.12 & 0.33 & 0.47 & 0.45 & 0.49 & 0.52 & 0.22 & 0.28 & 1.28 \\
\hline
\end{tabular}

Table 2. Average monthly ETo per day (mm/day) during calibration period 1980-2006

\begin{tabular}{c|c|c|c|c|c|c|c|c|c|c|c}
\hline Month & FAO56-PM & Dalton & Trabert & Meyer & Rohwer & Penman & Albrecht & Brockamp & WMO & Mahringer & Saif \\
\hline Jan & 1.36 & 1.29 & 1.34 & 1.28 & 1.31 & 1.35 & 1.47 & 1.35 & 1.39 & 1.36 & 1.45 \\
Feb & 1.99 & 1.71 & 1.77 & 1.69 & 1.74 & 1.78 & 1.94 & 1.77 & 1.84 & 1.79 & 1.92 \\
Mar & 1.90 & 1.70 & 1.76 & 1.68 & 1.73 & 1.77 & 1.93 & 1.76 & 1.83 & 1.78 & 1.91 \\
Apr & 2.80 & 2.48 & 2.53 & 2.47 & 2.50 & 2.54 & 2.66 & 2.53 & 2.58 & 2.55 & 2.64 \\
May & 2.58 & 2.53 & 2.53 & 2.55 & 2.53 & 2.53 & 2.53 & 2.54 & 2.53 & 2.54 & 2.53 \\
Jun & 4.18 & 4.14 & 4.22 & 4.13 & 4.18 & 4.23 & 4.42 & 4.21 & 4.30 & 4.23 & 4.39 \\
Jul & 3.55 & 3.74 & 3.72 & 3.77 & 3.73 & 3.73 & 3.70 & 3.74 & 3.72 & 3.73 & 3.71 \\
Aug & 3.18 & 3.31 & 3.29 & 3.33 & 3.30 & 3.30 & 3.28 & 3.31 & 3.29 & 3.31 & 3.29 \\
Sep & 3.85 & 3.93 & 3.91 & 3.96 & 3.92 & 3.91 & 3.89 & 3.92 & 3.91 & 3.92 & 3.89 \\
Oct & 3.87 & 3.51 & 3.58 & 3.50 & 3.54 & 3.59 & 3.75 & 3.58 & 3.65 & 3.60 & 3.73 \\
Nov & 1.77 & 1.75 & 1.75 & 1.76 & 1.75 & 1.75 & 1.77 & 1.77 & 1.76 & 1.77 & 1.76 \\
Dec & 2.06 & 2.10 & 2.04 & 2.14 & 2.09 & 2.06 & 1.95 & 2.07 & 2.02 & 2.06 & 1.97 \\
\hline
\end{tabular}

Table 3. Average monthly ETo per day ( $\mathrm{mm} /$ day) during validation period 2007-2018

\begin{tabular}{c|c|c|c|c|c|c|c|c|c|c|c}
\hline Month & FAO56-PM & Dalton & Trabert & Meyer & Rohwer & Penman & Albrecht & Brockamp & WMO & Mahringer & Saif \\
\hline Jan & 1.52 & 0.36 & 0.18 & 0.33 & 0.48 & 0.47 & 0.56 & 0.53 & 0.26 & 0.31 & 1.40 \\
Feb & 1.99 & 0.43 & 0.21 & 0.39 & 0.58 & 0.58 & 0.73 & 0.65 & 0.32 & 0.37 & 1.81 \\
Mar & 2.31 & 0.53 & 0.24 & 0.47 & 0.71 & 0.71 & 0.89 & 0.80 & 0.39 & 0.46 & 2.23 \\
Apr & 2.42 & 0.59 & 0.26 & 0.54 & 0.79 & 0.77 & 0.89 & 0.88 & 0.40 & 0.50 & 2.24 \\
May & 2.61 & 0.77 & 0.31 & 0.72 & 1.02 & 0.97 & 1.05 & 1.11 & 0.49 & 0.62 & 2.68 \\
Jun & 3.48 & 1.06 & 0.42 & 0.98 & 1.40 & 1.34 & 1.48 & 1.54 & 0.68 & 0.86 & 3.79 \\
Jul & 3.23 & 0.98 & 0.40 & 0.91 & 1.31 & 1.26 & 1.41 & 1.45 & 0.64 & 0.81 & 3.61 \\
Aug & 2.78 & 0.83 & 0.34 & 0.77 & 1.09 & 1.05 & 1.15 & 1.20 & 0.54 & 0.67 & 2.94 \\
Sep & 3.42 & 0.98 & 0.39 & 0.91 & 1.31 & 1.26 & 1.41 & 1.45 & 0.64 & 0.80 & 3.61 \\
Oct & 2.92 & 0.75 & 0.31 & 0.69 & 0.98 & 0.94 & 1.01 & 1.08 & 0.48 & 0.60 & 2.58 \\
Nov & 1.56 & 0.43 & 0.19 & 0.40 & 0.55 & 0.52 & 0.55 & 0.60 & 0.27 & 0.34 & 1.39 \\
Dec & 1.41 & 0.36 & 0.17 & 0.33 & 0.47 & 0.45 & 0.50 & 0.51 & 0.24 & 0.30 & 1.24 \\
\hline
\end{tabular}


Table 4. Seasonal average variation of ETo per day (mm/day) during period 1980-2018

\begin{tabular}{c|c|c|c|c|c|c|c|c|c|c|c}
\hline Month & FAO56-PM & Dalton & Trabert & Meyer & Rohwer & Penman & Albrecht & Brockamp & WMO & Mahringer & Saif \\
\hline Winter & 1.90 & 0.39 & 0.15 & 0.35 & 0.54 & 0.53 & 0.68 & 0.60 & 0.28 & 0.33 & 1.73 \\
Spring & 3.09 & 0.81 & 0.29 & 0.75 & 1.10 & 1.07 & 1.25 & 1.23 & 0.54 & 0.67 & 3.21 \\
Summer & 3.27 & 0.88 & 0.32 & 0.81 & 1.19 & 1.16 & 1.36 & 1.33 & 0.59 & 0.73 & 3.50 \\
Autumn & 2.00 & 0.49 & 0.17 & 0.45 & 0.65 & 0.62 & 0.69 & 0.72 & 0.31 & 0.39 & 1.80 \\
\hline
\end{tabular}

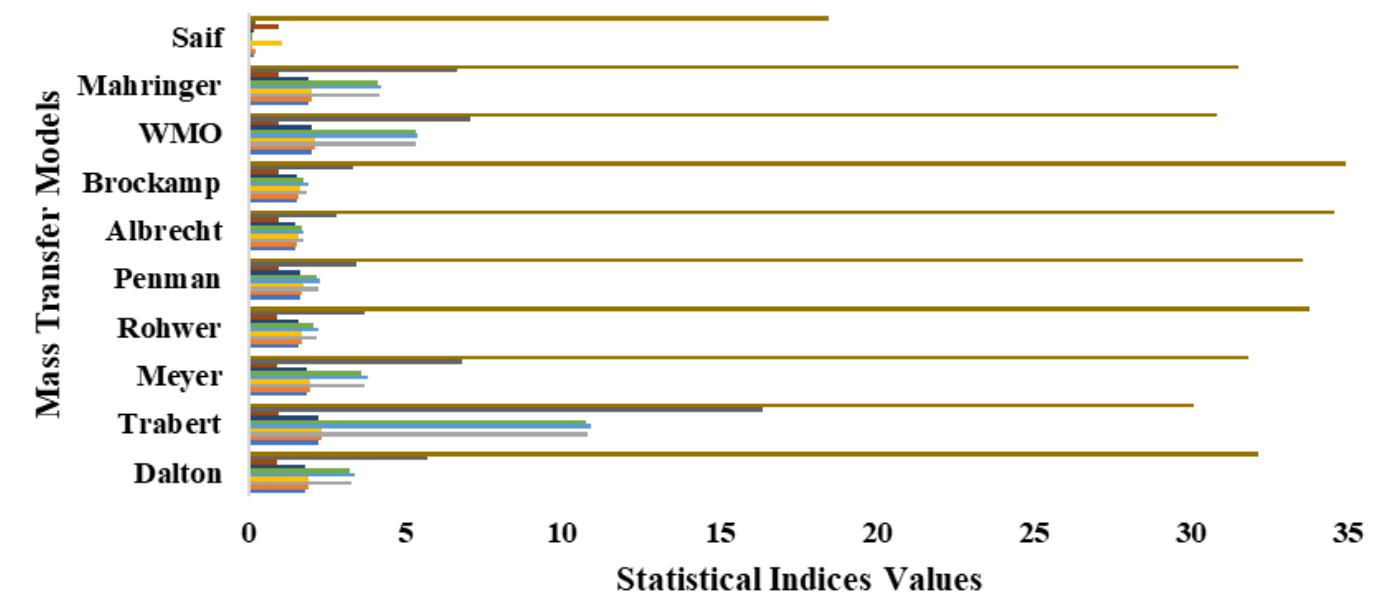

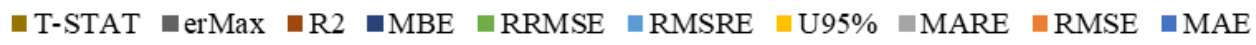

Figure 5. Error indices of all model during evaluation

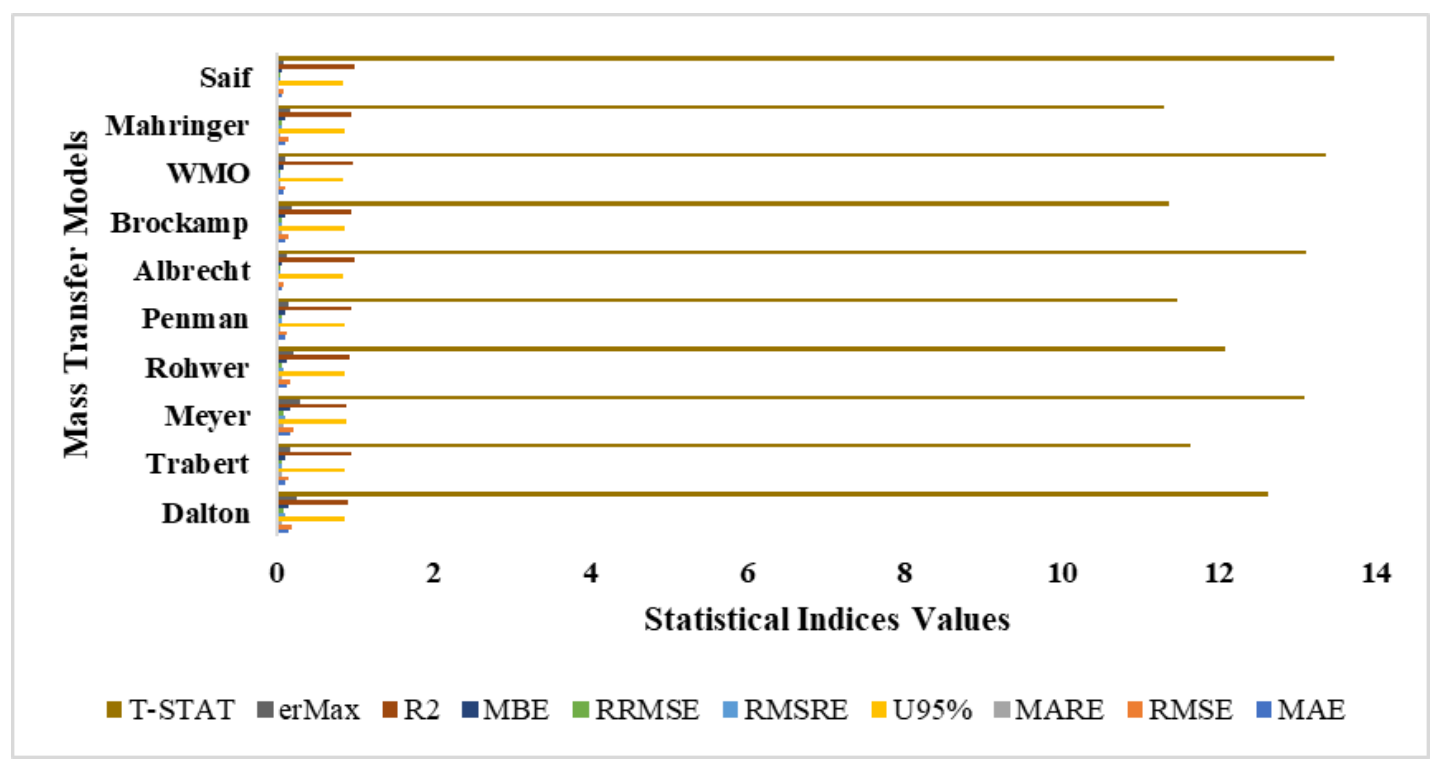

Figure 6. Error indices of all model during calibration

The models are ranked on the basis of multi-criteria decision-making techniques after evaluating, calibrating and validating the mass transfer equation against FAO56-PM model. The weightage was estimated by the CRITIC model as shown by Figure 8 . 


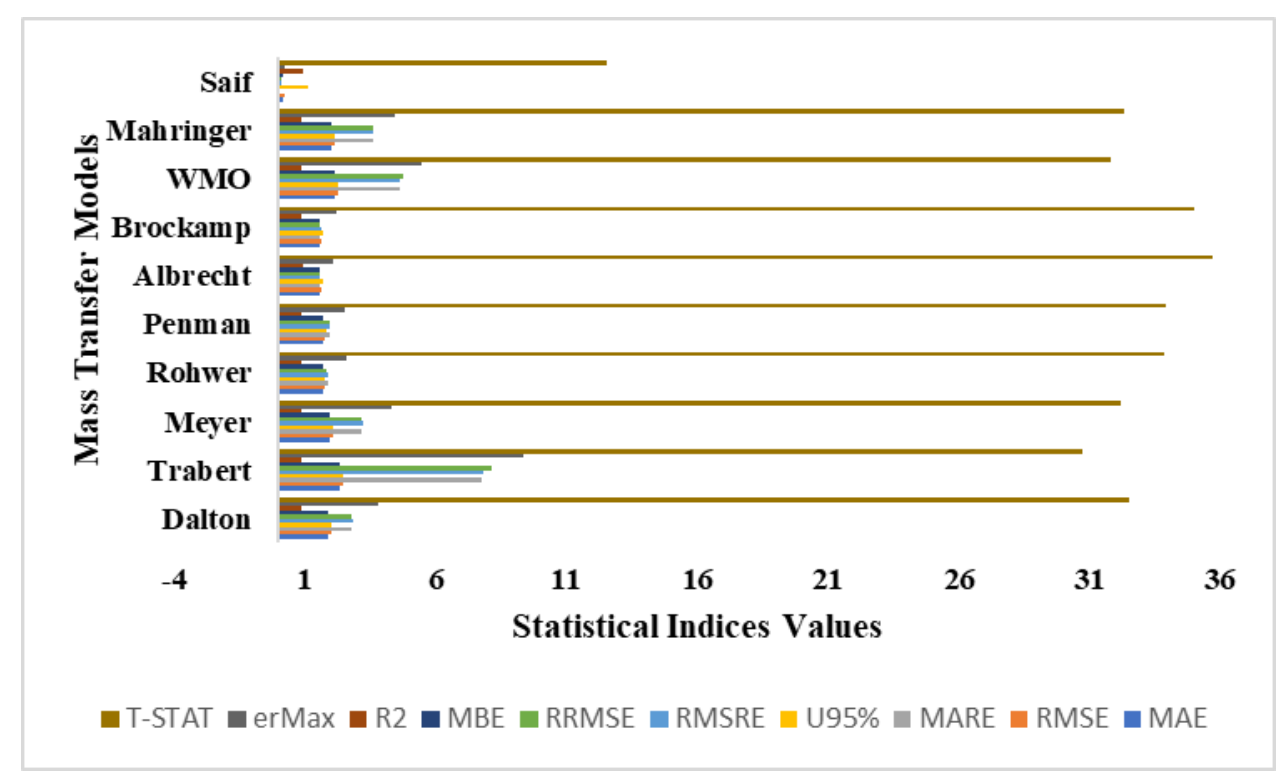

Figure 7. Error indices of all model during validation

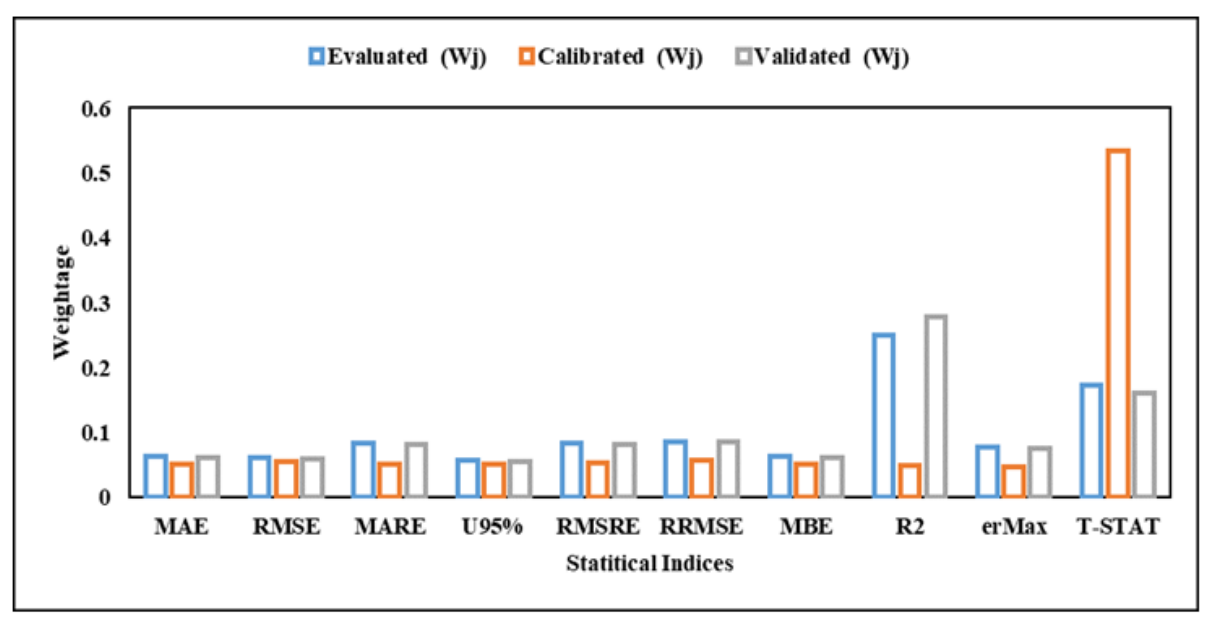

Figure 8. Weightage by CRITIC method

The performance score obtained by WSM, WPM, WASPAS, EDAS Models during evaluation calibration and validation. Furthermore, the performance score for validation as described in Figures 9-11 is computed by GPI. The findings clearly show that the Saif model is the one that better fits the study region. The ranking of the MCDM technique shows that Saif model is the best model in the study area. In addition, GPA validates the same result as indicated (Fig. 12). Trabert model showed equally worst performance during evaluation, calibration and validation respectively. Also, spearman's ranking correlation is estimated between MCDM and GPI as shown in Table 5. This study finds strong concordance among the results of three different MCDM methods. Although the low-ranked alternatives were not always positioned alike, the best and second-best choices were the same for all three results. Similarly, the least preferred alternative was also the same. The important fact to note here is, despite the variety of data synthesis procedures and level of intricacy involved with these methods, the suggestions were 
similar for the preferred alternatives. Since most of the water supply related problems seek to find the best suitable alternatives (Hajkowicz and Higgins, 2008; Sikder et al., 2015; Tirth et al., 2020), it could be inferred from the findings of the study that both simple and comprehensive MCDM methods yield the same output.

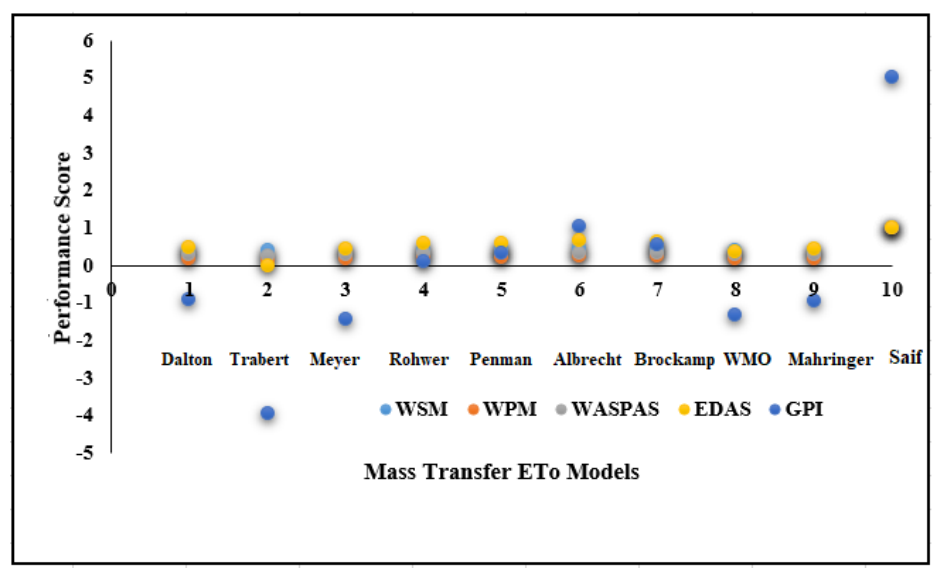

Figure 9. Performance score by different method during evaluation

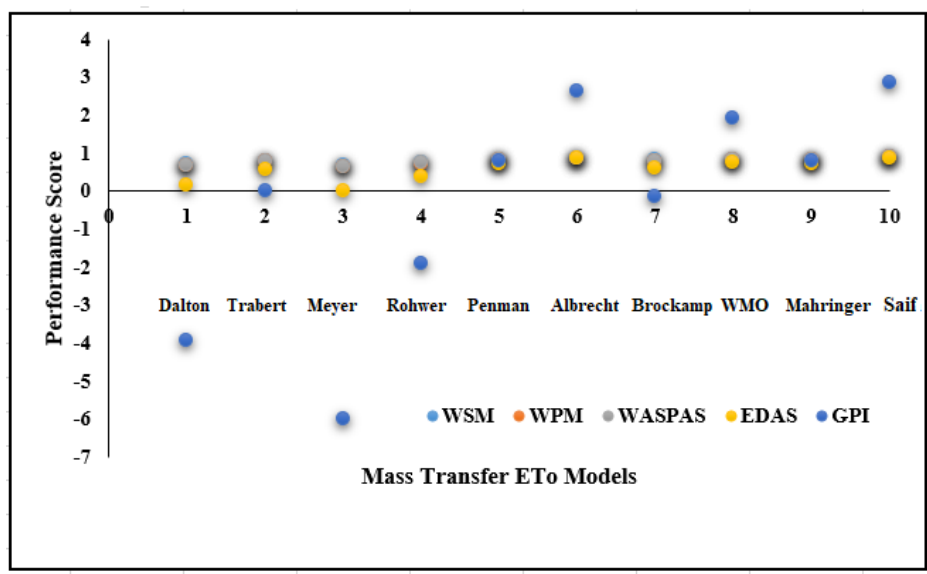

Figure 10. Performance score by different method during calibration

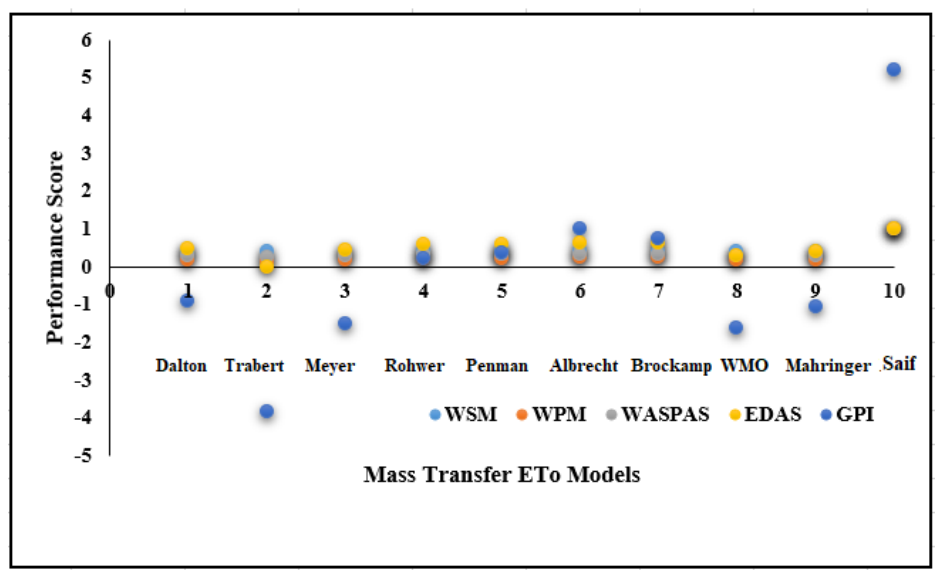

Figure 11. Performance score by different method during validation 


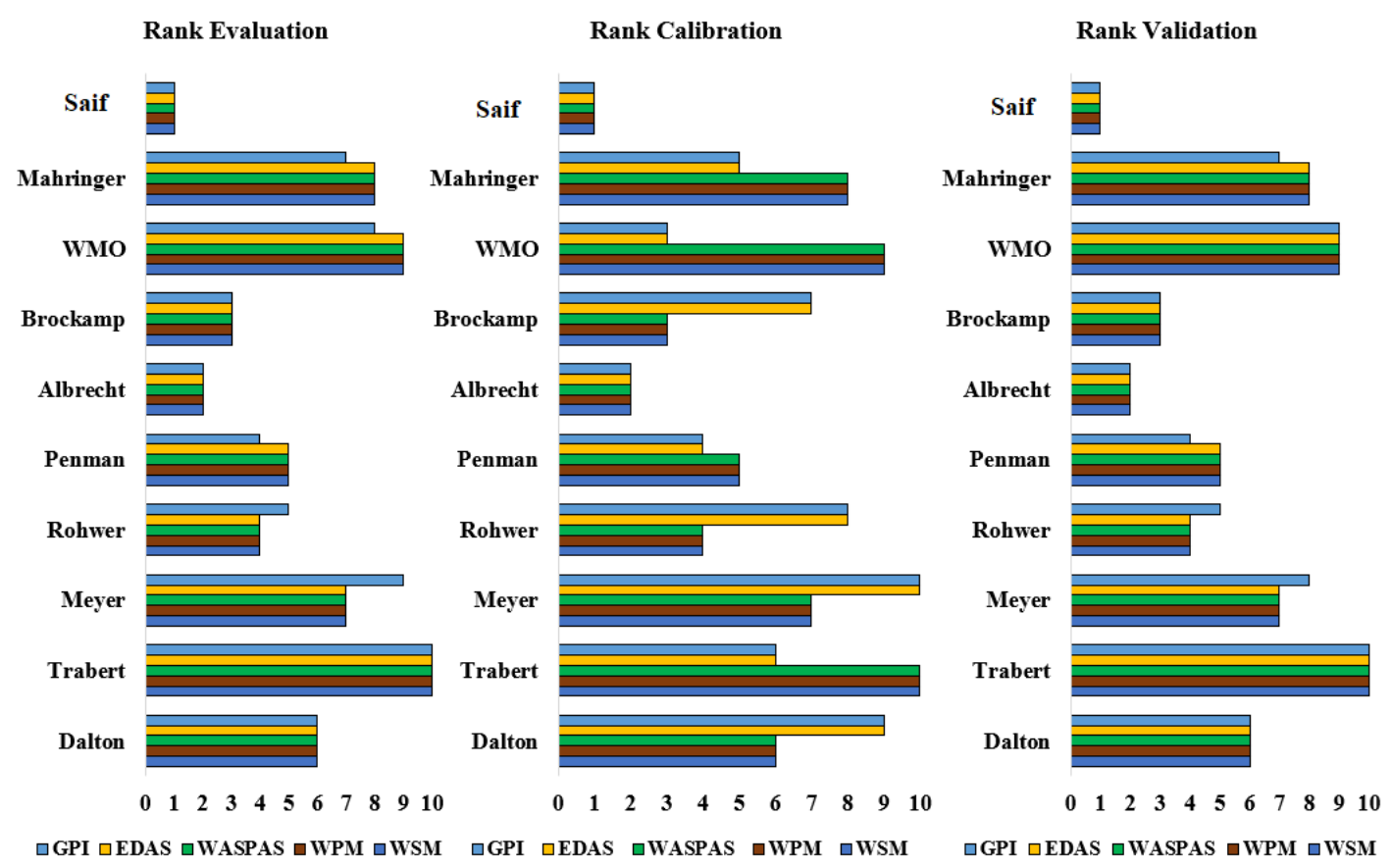

Figure 12. Ranking using MCDM and GPI model

Table 5. Spearman's rank correlation coefficient values

\begin{tabular}{|c|c|c|c|c|c|}
\hline \multicolumn{6}{|c|}{ Evaluation } \\
\hline & WSM & WPM & WASPAS & EDAS & GPI \\
\hline WSM & & 0.92 & 0.89 & 0.92 & 0.88 \\
\hline WPM & & & 0.99 & 1.00 & 0.96 \\
\hline WASPAS & & & & 0.99 & 0.99 \\
\hline EDAS & & & & & 0.96 \\
\hline \multicolumn{6}{|c|}{ Calibration } \\
\hline WSM & & 0.96 & 1.00 & 0.96 & 0.94 \\
\hline WPM & & & 0.96 & 1.00 & 0.98 \\
\hline WASPAS & & & & 0.96 & 0.94 \\
\hline EDAS & & & & & 0.98 \\
\hline \multicolumn{6}{|c|}{ Validation } \\
\hline WSM & & 0.89 & 0.94 & 0.89 & 0.95 \\
\hline WPM & & & 0.99 & 1.00 & 0.98 \\
\hline WASPAS & & & & 0.99 & 0.99 \\
\hline EDAS & & & & & 0.98 \\
\hline
\end{tabular}

\section{Conclusions}

This study was conducted to evaluate (period: 1980-2018), calibrate (period: 19802006) and further validate (period: 2007-2018) ten reference evapotranspiration models against standard FAO56 PM model in southern region (Abha) of Saudi Arabia. The performance scores (ranking) of aforementioned alternative models were computed based on ten statistical indices. The overall effect of these ten statistical indices were 
computed by multicriteria decision technique such as CRITIC (weightage of statistical indices), WSM, WPM, WASPAS and EDAS (ranking of alternative models). The ranking by MCDM technique were compared by GPI ranking using spearman ranking coefficient. The following inference can be made after achieving aforementioned objectives:

1. This work provides an integrated decision support tool for evaluating water resource management strategies

2. The calibrated equation performs better and hence provide consistent result.

3. The ranking by MCDM techniques (WSM, WPM, WASPAS and EDAS) shows that Saif model gives best performance while estimating reference evapotranspiration also GPI confirms the same.

4. MCDM models proved to be a versatile technique for selecting the most promising model in the study region.

5. The results are likely to help minimize the error in estimating reference evapotranspiration, and in addition the approach implemented in this study can be used in regions around the world with similar topography and climatic conditions.

6. Further research are required to assess the impact of using a reduced data set for daily ETo estimation hourly. In addition, in future the seasonal shifts in ETo must also be examined. Additionally, similar problem can be ranked by other available MCDM methods in the future.

Acknowledgments. The authors would like to acknowledge the Deanship of Scientific Research for proving administrative and financial support. Funding for this work has been provided by the Deanship of Scientific Research, King Khalid University, Ministry of Education, Kingdom of Saudi Arabia under research grant award number (G.R.P-212-41). The authors of current work wish to thank Universiti Tecknologi Malaysia, Johor Bahru for their facilities and Lab support. We would also like to thank general authority of the meteorological department, Abha, Asir region, Saudi Arabia for providing the weather data.

Funding: Funding for this work has been provided by the Deanship of Scientific Research; King Khalid University, Kingdom of Saudi Arabia, under award number G.R.P-212-41

Conflict of interests. The authors declare no conflict of interests.

\section{REFERENCES}

[1] Abo-Ghobar, H. M., Mohammad, S. (1995): Evapotranspiration measurement by lysimeters in a desert climate. - Arab Gulf Journal of Scientific Research 13(1): 109-122.

[2] Adalı, E. A., Işı1k, A. T. (2017): CRITIC and MAUT methods for the contract manufacturer selection problem. - European Journal of Multidisciplinary Studies 2(5): 93-101.

[3] Alblewi, B., Gharabaghi, B., Alazba, A. A., Mahboubi, A. A. (2015): Evapotranspiration models assessment under hyper-arid environment. - Arabian Journal of Geosciences 8(11): 9905-9912.

[4] Albrecht, F. (1950): Die Methoden zur Bestimmung der Verdunstung der natürlichen Erdoberfläche. - Archiv für Meteorologie, Geophysik und Bioklimatologie, Serie B 2(12): $1-38$.

[5] Ali, M., Jamil, B. (2019): Estimating diffuse solar radiation in India: performance characterization of generalized single-input empirical models. - Urban Climate 27: 314350 . 
[6] Ali, M. H., Shui, L. T. (2009): Potential evapotranspiration model for Muda irrigation project, Malaysia. - Water Resources Management 23(1): 57.

[7] Allen, R. (2008): Quality assessment of weather data and micrometeological flux-impacts on evapotranspiration calculation. - Journal of Agricultural Meteorology 64(4): 191-204.

[8] Allen, R. G., Pereira, L. S., Raes, D., Smith, M. (1998): Crop EvapotranspirationGuidelines for Computing Crop Water Requirements. - FAO Irrigation and Drainage Paper 56. FAO, Rome 300(9): D05109.

[9] Almorox, J., Quej, V. H., Martí, P. (2015): Global performance ranking of temperaturebased approaches for evapotranspiration estimation considering Köppen climate classes. - Journal of Hydrology 528: 514-522.

[10] Al-Omran, A. M., Al-Ghobari, H. M., Alazba, A. A. (2004): Determination of evapotranspiration of tomato and squash. - International Agricultural Engineering Journal 13(142): 27-36.

[11] Azhar, A. H., Perera, B. J. C. (2011): Evaluation of reference evapotranspiration estimation methods under southeast Australian conditions. - Journal of Irrigation and Drainage Engineering 137(5): 268-279.

[12] Behar, O., Khellaf, A., Mohammedi, K. (2015): Comparison of solar radiation models and their validation under Algerian climate - the case of direct irradiance. - Energy Conversion and Management 98: 236-251.

[13] Berti, A., Tardivo, G., Chiaudani, A., Rech, F., Borin, M. (2014): Assessing reference evapotranspiration by the Hargreaves method in north-eastern Italy. - Agricultural Water Management 140: 20-25.

[14] Bogawski, P., Bednorz, E. (2014): Comparison and validation of selected evapotranspiration models for conditions in Poland (Central Europe). - Water Resources Management 28(14): 5021-5038.

[15] Bormann, H. (2011): Sensitivity analysis of 18 different potential evapotranspiration models to observed climatic change at German climate stations. - Climatic Change 104(3-4): 729-753.

[16] Brockamp, B., Wenner, H. (1963): Verdunstungsmessungen auf den Steiner See bei Münster. - Dt Gewässerkundl Mitt 7: 149-154.

[17] Cadro, S., Uzunoviæ, M., Žurovec, J., Žurovec, O. (2017): Validation and calibration of various reference evapotranspiration alternative methods under the climate conditions of Bosnia and Herzegovina. - International Soil and Water Conservation Research 5(4): 309-324.

[18] Dalton, J. (1802): Experimental essays on the constitution of mixed gases; on the force of steam or vapor from water and other liquids in different temperatures, both in a Torricellian vacuum and in air; on evaporation and on the expansion of gases by heat. Memoirs of the Literary and Philosophical Society of Manchester 5(2): 535-602.

[19] Despotovic, M., Nedic, V., Despotovic, D., Cvetanovic, S. (2015): Review and statistical analysis of different global solar radiation sunshine models. - Renewable and Sustainable Energy Reviews 52: 1869-1880.

[20] Diakoulaki, D., Mavrotas, G., Papayannakis, L. (1995): Determing objective weights in multiple criteria problems: the CRITIC method. - Computers \& Operational Research 763-770.

[21] Djaman, K., Balde, A. B., Sow, A., Muller, B., Irmak, S., N'Diaye, M. K., Manneh, B., Moukoumbi, Y. D., Futakuchi, K., Saito, K. (2015): Evaluation of sixteen reference evapotranspiration methods under Sahelian conditions in the Senegal River Valley. Journal of Hydrology: Regional Studies 3: 139-159.

[22] Djaman, K., Tabari, H., Balde, A. B., Diop, L., Futakuchi, K., Irmak, S. (2016): Analyses, calibration and validation of evapotranspiration models to predict grassreference evapotranspiration in the Senegal river delta. - Journal of Hydrology: Regional Studies 8: 82-94. 
[23] Djaman, K., Koudahe, K., Allen, S., O’Neill, M., Irmak, S. (2017): Validation of Valiantzas' reference evapotranspiration equation under different climatic conditions. Irrigation \& Drainage Systems Engineering 6(3): 196.

[24] ElNesr, M., Alazba, A., Abu-Zreig, M. (2010): Spatio-temporal variability of evapotranspiration over the Kingdom of Saudi Arabia. - Applied Engineering in Agriculture 26(5): 833-842.

[25] Gueymard, C. A. (2014): A review of validation methodologies and statistical performance indicators for modeled solar radiation data: towards a better bankability of solar projects. - Renewable and Sustainable Energy Reviews 39: 1024-1034.

[26] Gupta, A. P., Harboe, R., Tabucanon, M. T. (2000): Fuzzy multiple-criteria decision making for crop area planning in Narmada River basin. - Agricultural Systems 63(1): 118.

[27] Hajkowicz, S., Higgins, A. (2008): A comparison of multiple criteria analysis techniques for water resource management. - European Journal of Operational Research 184(1): 255265.

[28] Irmak, S., Irmak, A., Allen, R. G., Jones, J. W. (2003): Solar and net radiation-based equations to estimate reference evapotranspiration in humid climates. - Journal of Irrigation and Drainage Engineering 129(5): 336-347.

[29] Islam, S., Abdullah, R. A. B., Algahtani, A., Irshad, K., Hirol, H. (2019a): Performance of vapour pressure models in the computation of vapour pressure and evapotranspiration in Abha, Asir region, Saudi Arabia. - Applied Ecology and Environmental Research 17(4): 9691-9715.

[30] Islam, S., Abdullah, R. A. B., Algahtani, A., Irshad, K., Hirol, H. (2019b): Performance evaluation off mass transfer-based method using global performance index in semi-arid region, Saudi Arabia. - Applied Ecology and Environmental Research 17(5): 1112111141.

[31] Islam, S., Abdullah, R. A. B., Badruddin, I. A., Algahtani, A., Shahid, S., Irshad, K., Mallick, J., Hirol, H., Alsubih, M., Elouni, M. H., Kahla, N. B.(2020): Calibration and validation of reference evapotranspiration models in semi-arid conditions. - Applied Ecology and Environmental Research 18(1): 1361-1386.

[32] Janssen, R., Goosen, H., Verhoeven, M. L., Verhoeven, J. T., Omtzigt, A. Q. A., Maltby, E. (2005): Decision support for integrated wetland management. - Environmental Modelling \& Software 20(2): 215-229.

[33] Keshavarz Ghorabaee, M., Zavadskas, E. K., Olfat, L., Turskis, Z. (2015): Multi-criteria inventory classification using a new method of evaluation based on distance from average solution (EDAS). - Informatica 26(3): 435-51.

[34] Kiafar, H., Babazadeh, H., Marti, P., Kisi, O., Landeras, G., Karimi, S., Shiri, J. (2017): Evaluating the generalizability of GEP models for estimating reference evapotranspiration in distant humid and arid locations. - Theoretical and Applied Climatology 130(1-2): 377-389.

[35] Kisi, O., Zounemat-Kermani, M. (2014): Comparison of two different adaptive neurofuzzy inference systems in modelling daily reference evapotranspiration. - Water Resources Management 28(9): 2655-2675.

[36] Lang, D., Zheng, J., Shi, J., Liao, F., Ma, X., Wang, W., Chen, X., Zhang, M. (2017): A comparative study of potential evapotranspiration estimation by eight methods with FAO Penman-Monteith method in southwestern China. - Water 9(10): 734.

[37] Li, M. F., Tang, X. P., Wu, W., Liu, H. B. (2013): General models for estimating daily global solar radiation for different solar radiation zones in mainland China. - Energy Conversion and Management 70: 139-148.

[38] Mahringer, W. (1970): Verdunstungsstudien am Neusiedler See. - Archiv für Meteorologie, Geophysik und Bioklimatologie, Serie B 18(1): 1-20. 
[39] Makropoulos, C. K., Natsis, K., Liu, S., Mittas, K., Butler, D. (2008): Decision support for sustainable option selection in integrated urban water management. - Environmental Modelling and Software 23(12): 1448-1460.

[40] Mann, S. H., Evangelos, T. (1989): An examination of the effectiveness of multidimensional decision-making methods. - International Journal of Decision Support Systems 5(3): 303-12.

[41] Mardani, A., Zavadskas, E. K., Govindan, K., Amat Senin, A., Jusoh, A. (2016): VIKOR technique: a systematic review of the state of the art literature on methodologies and applications. - Sustainability 8(1): 37.

[42] Mehdizadeh, S. (2018): Estimation of daily reference evapotranspiration (ETo) using artificial intelligence methods: offering a new approach for lagged ETo data-based modeling. - Journal of Hydrology. 559: 794-812.

[43] Meyer, A. (1926): Über einige Zusammenhänge zwischen Klima und Boden in Europa. Doctoral Dissertation, ETH, Zurich.

[44] Minatour, Y., Bonakdari, H., Zarghami, M., Bakhshi, M. A. (2015): Water supply management using an extended group fuzzy decision-making method: a case study in north-eastern Iran. - Applied Water Science 5(3): 291-304.

[45] Muhammad, M. K. I., Nashwan, M. S., Shahid, S., Ismail, T. B., Song, Y. H., Chung, E. S. (2019): Evaluation of empirical reference evapotranspiration models using compromise programming: a case study of Peninsular Malaysia. - Sustainability 11(16): 4267.

[46] Mulaudzi, T. S., Maluta, N. E., Sankaran, V. (2015): Evaluation of the global solar irradiance in the Vhembe district of Limpopo Province, South Africa, using different theoretical models. Evaluation of the global solar irradiance in the Vhembe district of Limpopo Province, South Africa, using different theoretical models. - Turkish Journal of Physics 39(3): 264-271.

[47] Pandey, P. K., Dabral, P. P., Pandey, V. (2016): Evaluation of reference evapotranspiration methods for the northeastern region of India. - International Soil and Water Conservation Research 4(1): 52-63.

[48] Pandey, V., Pandey, P. K. (2018): Calibration and ranking of Valiantzas reference evapotranspiration equations under the humid climate of northeast India. - Journal of Water and Climate Change: jwc2018305.

[49] Penman, H. L. (1948): Natural evaporation from open water, bare soil and grass. Proceedings of the Royal Society of London. Series A. Mathematical and Physical Sciences 193(1032): 120-145.

[50] Pietersen, K. (2006): Multiple criteria decision analysis (MCDA): A tool to support sustainable management of groundwater resources in South Africa. - Water SA 32(2): 119-128.

[51] Qin, X. S., Huang, G. H., Chakma, A., Nie, X. H., Lin, Q. G. (2008): A MCDM-based expert system for climate-change impact assessment and adaptation planning - a case study for the Georgia Basin, Canada. - Expert Systems with Applications 34(3): 21642179.

[52] Rohwer, C. (1931): Evaporation from a Free Water Surface. - US Dept. of Agr. Tech. Bull. 271, Washington.

[53] Šaparauskas, J., Kazimieras Zavadskas, E., Turskis, Z.( 2011): Selection of facade's alternatives of commercial and public buildings based on multiple criteria. - International Journal of Strategic Property Management 15(2): 189-203.

[54] Senent-Aparicio, J., Pérez-Sánchez, J., Carrillo-García, J., Soto, J. (2017): Using SWAT and Fuzzy TOPSIS to assess the impact of climate change in the headwaters of the Segura River Basin (SE Spain). - Water 9(2): 149.

[55] Sentelhas, P. C., Gillespie, T. J., Santos, E. A. (2010): Evaluation of FAO PenmanMonteith and alternative methods for estimating reference evapotranspiration with 
missing data in Southern Ontario, Canada. - Agricultural Water Management 97(5): pp.635-644.

[56] Shiri, J. (2018): Improving the performance of the mass transfer-based reference evapotranspiration estimation approaches through a coupled wavelet-random forest methodology. - Journal of Hydrology 561: 737-750.

[57] Sikder, A. H. M. K., Salehin, M. (2015): Multi-criteria decision making methods for rural water supply: a case study from Bangladesh. - Water Policy 17(6): 1209-1223.

[58] Srdjevic, B., Medeiros, Y. D. P., Faria, A. S. (2004): An objective multi-criteria evaluation of water management scenarios. - Water resources management 18(1): 35-54.

[59] Stone, R. J. (1993): Improved statistical procedure for the evaluation of solar radiation estimation models. - Solar Energy 51(4): 289-291.

[60] Tabari, H., Grismer, M. E., Trajkovic, S. (2013): Comparative analysis of 31 reference evapotranspiration methods under humid conditions. - Irrigation Science 31(2): 107-117.

[61] Tirth, V., Singh, R. K., Islam, S., Badruddin, I. A., Abdullah, R. A. B., Algahtani, A., Mahmoud, E. R., Arabi, A., Shukla, N. K., Gupta, P. (2020): Kharif crops selection for sustainable farming practices in the Rajasthan - India using multiple attribute-based decision-making. - Agronomy 10(4): 536.

[62] Trabert, W. (1896): Neue Beobachtungen über Verdampfungsgeschwindigkeiten. Meteorol Z 13: 261-263.

[63] Valiantzas, J. D. (2013): Simplified forms for the standardized FAO-56 PenmanMonteith reference evapotranspiration using limited weather data. - Journal of Hydrology 505: 13-23.

[64] Valipour, M. (2015): Investigation of Valiantzas' evapotranspiration equation in Iran. Theoretical and Applied Climatology 121(1-2): 267-278.

[65] Valipour, M. (2017): Calibration of mass transfer-based models to predict reference crop evapotranspiration. - Applied Water Science 7(2): 625-635.

[66] Willmott, C. J., Matsuura, K. (2005): Advantages of the mean absolute error (MAE) over the root mean square error (RMSE) in assessing average model performance. - Climate Research 30(1): 79-82.

[67] Winter, T. C., Rosenberry, D. O., Sturrock, A. M. (1995): Evaluation of 11 equations for determining evaporation for a small lake in the north central United States. - Water Resources Research 31(4): 983-993.

[68] WMO (1966): Measurement and Estimation of Evaporation and Evapotranspiration. Tech. Pap. (CIMO-Rep) 83, Genf.

[69] Xu, C. Y., Singh, V. P. (2001): Evaluation and generalization of temperature-based methods for calculating evaporation. - Hydrological Processes 15(2): 305-319.

[70] Xu, C. Y., Singh, V. P. (2002): Cross comparison of empirical equations for calculating potential evapotranspiration with data from Switzerland. - Water Resources Management 16(3): 197-219.

[71] Xu, J., Peng, S., Ding, J., Wei, Q., Yu, Y. (2013): Evaluation and calibration of simple methods for daily reference evapotranspiration estimation in humid East China. Archives of Agronomy and Soil Science 59(6): 845-858.

[72] Zarghami, M., Abrishamchi, A., Ardakanian, R. (2008): Multi-criteria decision making for integrated urban water management. - Water Resources Management 22(8): 10171029.

[73] Zhai, L., Feng, Q., Li, Q., Xu, C. (2010): Comparison and modification of equations for calculating evapotranspiration (ET) with data from Gansu Province, Northwest China. Irrigation and Drainage 59(4): 477-490. 